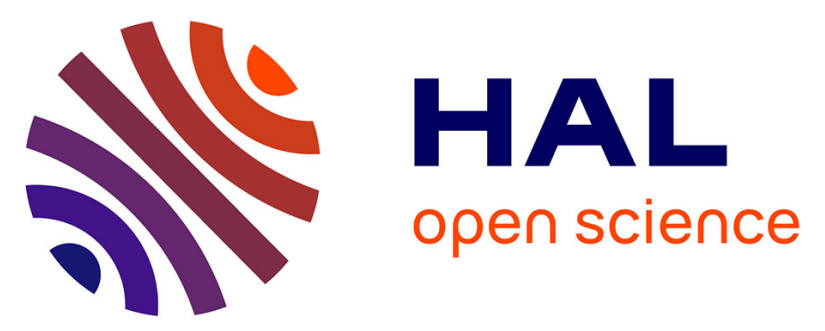

\title{
Experimental investigation on ammonia combustion behavior in a spark-ignition engine by means of laminar and turbulent expanding flames
}

Charles Lhuillier, Pierre Brequigny, Francesco Contino, Christine

Mounaïm-Rousselle

\section{To cite this version:}

Charles Lhuillier, Pierre Brequigny, Francesco Contino, Christine Mounaïm-Rousselle. Experimental investigation on ammonia combustion behavior in a spark-ignition engine by means of laminar and turbulent expanding flames. Proceedings of the Combustion Institute, In press, 38 (4), pp.5859-5868. 10.1016/j.proci.2020.08.058 . hal-02965745

\section{HAL Id: hal-02965745 \\ https://hal.science/hal-02965745}

Submitted on 13 Oct 2020

HAL is a multi-disciplinary open access archive for the deposit and dissemination of scientific research documents, whether they are published or not. The documents may come from teaching and research institutions in France or abroad, or from public or private research centers.
L'archive ouverte pluridisciplinaire HAL, est destinée au dépôt et à la diffusion de documents scientifiques de niveau recherche, publiés ou non, émanant des établissements d'enseignement et de recherche français ou étrangers, des laboratoires publics ou privés. 


\section{Experimental investigation on ammonia combustion behavior in a}

\section{spark-ignition engine by means of laminar and turbulent expanding}

\section{flames}

Charles LHUILLIER ${ }^{1,2,3}$, Pierre BREQUIGNY ${ }^{1}$, Francesco CONTINO ${ }^{4}$, Christine MOUNAÏMROUSSELLE ${ }^{1}$

${ }^{1}$ Univ. Orléans, INSA-CVL, EA 4229 - PRISME, F-45072, Orléans, France

${ }^{2}$ Vrije Univ. Brussel, FLOW - Thermo and Fluid Dynamics Research Group, Belgium

${ }^{3}$ Vrije Univ. Brussel, Univ. Libre Bruxelles, BURN - Combustion and Robust Optimization Joint Research Group, Belgium

${ }^{4}$ iMMC, UCLouvain, Belgium

Colloquium: Reciprocating IC Engines (alternate: Turbulent Flames)

Total length of paper: 6106 words

Word count:

\begin{tabular}{|l|l|}
\hline Abstract & 282 \\
\hline Nomenclature & 236 \\
\hline Main text & 3027 \\
\hline References & 682 \\
\hline Equation 1 & 46 \\
\hline Equation 2 & 23 \\
\hline Figure 1 & 96 \\
\hline Figure 2 & 282 \\
\hline Figure 3 & 231 \\
\hline Figure 4 & 236 \\
\hline Figure 5 & 181 \\
\hline Figure 6 & 170 \\
\hline Figure 7 & 182 \\
\hline Figure 8 & 237 \\
\hline Figure 9 & 147 \\
\hline Figure 10 & 150 \\
\hline Table 1 & 182 \\
\hline Total(excl. abstract) & 6106 \\
\hline
\end{tabular}

Supplemental material is available. Color figures only in the online version. 


\begin{abstract}
Ammonia combustion appears as a meaningful way to retrieve stored amounts of excess variable renewable energy, and the spark-ignition (SI) engine has been proposed as a practical conversion system. The present work aims at elucidating the combustion characteristics of ammonia blends in engine-relevant turbulent conditions. To that end, laminar and turbulent flame experiments were conducted in a constant-volume vessel at engine-relevant conditions of $445 \mathrm{~K}$ and $0.54 \mathrm{MPa}$ to assess the combustion behavior of ammonia/hydrogen/air, ammonia/methane/air and methane/hydrogen/air mixtures observed in an all-metal single-cylinder SI engine. Results show that the respective accelerating or decelerating effects of hydrogen or methane enrichment observed in the SI engine could not be sufficiently explained by the laminar burning velocities of the mixtures. Since the latter are very low, the studied combustion regimes are at the boundary between the thin and broken reaction zones regimes, and thus strongly influenced by flame-turbulence interactions. The quantification of the flame response to turbulence shows much higher effects for ammonia blends, than for methane-based fuels. The aforementioned opposite effects of ammonia enrichment with hydrogen or methane are observed on the turbulent burning velocity during the turbulent flame experiments and correlated to the thermochemical properties of the reactants and the flame sensitivity to stretch. The latter may explain an unexpected bending effect on the turbulent-to-laminar velocity ratio when increasing the hydrogen fraction in the ammonia/hydrogen blend. Nevertheless, a very good correlation of the turbulent velocity was found with the Karlovitz and Damköhler numbers, that suggests that ammonia combustion in SI engines may be described following the usual turbulent combustion models. This encourages further investigations on ammonia combustion for the optimization of practical systems, by means of dedicated experiments and numerical simulations.
\end{abstract}

\title{
Keywords
}

Ammonia; Hydrogen; Methane; SI engine; Turbulent flame; 


\section{Nomenclature}

$c_{\mathrm{p}}$ : isobaric specific heat capacity.

$K a$ : Karlovitz number.

$L_{\mathrm{b}}$ : burnt-side Markstein length.

$L_{\mathrm{T}}$ : integral turbulent length scale.

Le: Lewis number.

Ma: Markstein number.

$R_{\mathrm{s}}$ : flame surface area equivalent radius.

$R e$ : Reynolds number.

$S$ : burning velocity.

$u^{\prime}$ : longitudinal turbulence intensity.

$V$ : flame propagation velocity.

$x$ : mole fraction.

Greek symbols

$\delta$ : flame thickness

$\lambda$ : gas thermal conductivity.

$\phi$ : equivalence ratio.

$\rho$ : density.

Subscripts

additive: refers to $\mathrm{H}_{2}$ or $\mathrm{CH}_{4}$ added in the main fuel. 
b: burned.

eff: effective.

L: laminar.

$\mathrm{T}$ : turbulent.

u: unburned

Superscripts

0: unstretched.

\section{Introduction}

Ammonia $\left(\mathrm{NH}_{3}\right)$ is recognized as a carbon-free sustainable electro-fuel, useful to transport and store excess energy from variable renewable sources in complement to hydrogen $\left(\mathrm{H}_{2}\right)$ [1]. Ammonia combustion in gas turbines or internal combustion engines is a meaningful approach to retrieve the stored energy, especially in hard-to-electrify applications such as maritime transport. However, current lack of understanding makes it the subject of several studies as underlined in [2-4].

In Spark-Ignition (SI) engines, the assessment of laminar combustion properties remains a meaningful first-order approach to describe the behavior of air-fuel mixtures, since it correlates to the initial flame kernel growth that governs the combustion resilience to cycle-to-cycle variability [5]. However, experimental laminar burning velocity (LBV) data for $\mathrm{NH}_{3}$-based mixtures are still sparse in the literature, especially at SI engine-relevant conditions, i.e. high temperature and pressure. For example, Hayakawa et al. measured the LBV and Markstein length of $\mathrm{NH}_{3}$ /air flames at various equivalence ratios $(\phi)$, at $298 \mathrm{~K}$ and up to $0.5 \mathrm{MPa}[6]$. Ichikawa et al. carried out similar measurements under the same initial conditions for stoichiometric $\mathrm{NH}_{3} / \mathrm{H}_{2} /$ air flames with $0-100 \mathrm{vol} . \% \mathrm{H}_{2}$ [7]. Okafor et al. provided another dataset for ammonia blended with methane $\left(\mathrm{CH}_{4}\right)$ in air (up to 53 vol.\% $\% \mathrm{NH}_{3}$ in the fuel) at various $\phi, 298 \mathrm{~K}$ and up to $0.5 \mathrm{MPa}$ [8]. Recently, Lhuillier et al. attempted to partially fill in that gap with an extensive experimental LBV study by means of the outwardly propagating spherical 
flame (OPSF) method covering a wide range of $\phi(0.8$ to 1.4$)$, fuel hydrogen fractions ( 0 to 60 vol.\%) and initial temperatures (298 to $473 \mathrm{~K})$ at atmospheric pressure [9]. Kinetic models of ammonia oxidation have been improved recently but still lack comprehensive experimental data to be validated over the range relevant for SI engine conditions [10-16].

Recently, we presented premixed $\mathrm{NH}_{3}$ /air fueling of a modern SI engine with satisfactory stability and performances [17-19]. Spark-ignition timing (SIT) advance, intake pressure increase, and $\mathrm{H}_{2}$ enrichment of the fuel widened the stability range and improved performances. An analysis based on the LBV was not sufficient to fully elucidate the behavior observed in terms of combustion stability and cyclic variation when varying the latter parameters, especially for lean $\mathrm{H}_{2}$-enriched mixtures. Therefore, since ammonia mixtures cause operation in unusual turbulent combustion regimes, it is necessary to investigate the combustion of $\mathrm{NH}_{3}$-based mixtures in controlled turbulent conditions, in order to bring deeper understanding, as well as experimental data for the validation of future adapted models [20]. Ichikawa et al. performed ammonia/methane/air turbulent flames experiments on a nozzle burner at $0.5 \mathrm{MPa}$ and $298 \mathrm{~K}$ for $\phi=0.9$ and $0-39 \mathrm{vol} . \% \mathrm{NH}_{3}$ in fuel [21]. They reported a decreasing turbulent-to-laminar velocity ratio when increasing the ammonia content, mainly explained by the decrease of the flame surface density. Ichimura et al. conducted $\mathrm{NH}_{3} /$ air turbulent flames experiments in a fan-stirred constant-volume vessel at $298 \mathrm{~K}$ and $0.1 \mathrm{MPa}$ for $\phi=0.6-1.3$ and average turbulence intensities $u^{\prime}=0.32-1.61$ [22]. The longitudinal integral length scale reported $\left(L_{\mathrm{T}}=20.9 \mathrm{~mm}\right)$ is one order of magnitude higher than typical SI engines values and most of the studied flames are in the thin reaction zones regime. Extinction-free flame propagation could be achieved at the highest $u$ ' for $\phi=0.9$, and lean mixtures showed successful propagation over a wider Karlovitz number $(K a)$ range than rich ones, indicating a better resistance to turbulence-induced extinction. This may result from thermodiffusive accelerating effects, as inferred by the authors from lower-than-unity Lewis numbers $(L e)$ and near-zero Markstein numbers. Such effects are well identified in the literature [23-25] and also invoked to explain the higher turbulent-to-laminar velocity ratios of lean ammonia mixtures in oxygenenriched air condition and identical configuration in [26]. 
The objective of the present study is to partially elucidate the phenomena responsible for successful stable ammonia combustion with or without help of combustion promoters in modern SI engines, by combining experimental data obtained in two complementary setups, namely a single-cylinder SI engine and a constant-volume combustion vessel in laminar and turbulent configurations. Since hydrogen combustion is strongly influenced by preferential transport phenomena due to its high molecular diffusivity, it appears meaningful to assess the turbulent flame propagation properties of $\mathrm{NH}_{3} / \mathrm{H}_{2} /$ air in comparison with $\mathrm{NH}_{3} / \mathrm{CH}_{4} /$ air and $\mathrm{CH}_{4} / \mathrm{H}_{2} /$ air mixtures.

\section{Experimental and numerical methods}

\subsection{SI engine set-up and conditions}

Experiments were conducted in a four-stroke pentroof chamber single-cylinder all-metal SI engine (already described in $[17,18]$ ) with a 10.5:1 compression ratio fueled with premixed gaseous mixtures at fixed intake conditions (323K and $0.1 \mathrm{MPa}$ ) and $1500 \mathrm{rpm}$. Investigated mixtures cover fuel blends summarized in Table 1, with $x_{\text {additive }}$ the mole fraction of $\mathrm{H}_{2}$ or $\mathrm{CH}_{4}$ in the base fuel $\left(\mathrm{NH}_{3}\right.$ or $\left.\mathrm{CH}_{4}\right)$ and $\phi=0.9-1.0-1.1$. In order to conduct meaningful comparisons, the SIT was fixed at 42 Crank Angle Degrees (CAD) before Top Dead Center (TDC), optimized for $\mathrm{NH}_{3} /$ air combustion. At this SIT, estimated thermodynamic conditions were $445 \mathrm{~K}$ and $0.54 \mathrm{MPa}$ and in-cylinder turbulence characteristics $L_{\mathrm{T}}=1.48 \mathrm{~mm}$ and $u^{\prime}=2.44 \mathrm{~m} . \mathrm{s}^{-1}$, obtained from Converge CFD simulations (Avdic A., Modeling and Simulation of Ammonia Combustion in Spark Ignition Engines, Converge user conference, March 2019, Barcelona, Spain). A Heat Release Rate (HRR) analysis yields the crank angles CA10, CA50, CA90 corresponding to $10,50,90 \%$ of mass burned and highlight the flame propagation specificities of ammonia combustion. 


\section{Table 1}

Investigated fuel blends.

\begin{tabular}{lll}
\hline Base fuel & $x_{\mathrm{H}_{2}}(\%)$ & $x_{\mathrm{CH}_{4}}(\%)$ \\
\hline $\mathrm{NH}_{3}$ & $0,5,10,15$ & - \\
$\mathrm{NH}_{3}$ & - & $5,10,15$ \\
$\mathrm{CH}_{4}$ & $0,5,10,15$ & - \\
\hline
\end{tabular}

\subsection{Laminar flames set-up and conditions}

The constant-volume spherical vessel used in the present study was fully described in [27], along with the experimental procedure that was updated with ammonia flames specificities in [9]. The fuel blends and $\phi$ are identical to those of the engine study (Table 1) but $\mathrm{CH}_{4} / \mathrm{H}_{2}$ blends were limited to $5 \mathrm{vol} . \% \mathrm{H}_{2}$. The in-cylinder engine conditions at SIT were chosen for the unburned gas $(445 \mathrm{~K}, 0.54 \mathrm{MPa})$. A minimum of three identical tests were performed for each condition. Experimental LBVs and Markstein lengths were extracted from the Schlieren-based flames propagation history by means of non-linear zero-stretch extrapolation. Even though sparse cracks typical for cellular instability could be observed under those thermo-diffusively and hydro-dynamically unstable conditions, the reproducibility of the measurement was very good with standard deviations below $10 \%$.

\subsection{Turbulent flames set-up and conditions}

In this part of the study, the constant-volume vessel in Sec.2.2 was used with six identical fans continuously stirring the mixture during the combustion, as in $[25,28]$. A region of mean homogeneous and isotropic turbulence was identified in a radius of $20 \mathrm{~mm}$ around the vessel center [29] with a longitudinal integral length scale of $L_{\mathrm{T}}=3.4 \mathrm{~mm}$. For this study, two values of mean turbulence intensities, $u$ ', induced by different fan rotation speeds were chosen $\left(1.04 \mathrm{~m} \cdot \mathrm{s}^{-1}\right.$ and $\left.1.73 \mathrm{~m} \cdot \mathrm{s}^{-1}\right)$. The unburned gas conditions were identical to the laminar experiments with the same fuel blends (Table 1) but only at $\phi=0.9$. Each experiment was repeated at least ten times. Error bars reported with the 
results are standard deviations. Examples of turbulent flames images obtained from the Schlieren technique are showed in Fig. 1 and in the SM.
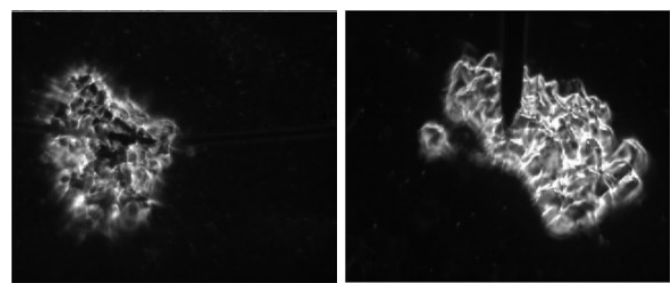

Fig.1. Example of double Schlieren images of a $\mathrm{NH}_{3} /$ air turbulent flame at $u^{\prime}=1.73 \mathrm{~m} . \mathrm{s}^{-1}$.

Thanks to the determination of a flame surface area equivalent radius $R_{\mathrm{S}}$ from the flame contours, a burned side equivalent turbulent propagation velocity was calculated as $V_{\mathrm{T}}=\mathrm{d} R_{\mathrm{S}} / \mathrm{d} t$ and transposed on the unburned side by the burned-to-unburned density ratio $\rho_{\mathrm{b}} / \rho_{\mathrm{u}}$ at equilibrium. Due to very low LBVs, most of the $\mathrm{NH}_{3}$-blend flames were conveyed away from the vessel center by large turbulent structures, affecting the global spherical shape as seen in Fig.1. This results in a limited range of observable radii and in the fact that no steady propagation regime could be reached presently. However, the observations made at small radii are still very valuable, since combustion propagation and stability are mainly driven by the initial flame kernel growth in SI engines [30]. Thus, most of comparisons are made at constant radius $R_{\mathrm{S}}=10 \mathrm{~mm}$ in the following.

\subsection{Kinetics simulation}

LBVs and flame temperature profiles were estimated by means of the 1D premixed freely propagating adiabatic flame model in Cantera 2.4.0, as well as other mixture properties, such as the burned-tounburned density ratio thanks to equilibrium calculations [31]. Different kinetic models (Nakamura et al. [12], Shrestha et al.[14], Otomo et al. [13] and Okafor et al. [15]) were used. The first three were chosen for their relatively good accuracy with respect to $\mathrm{NH}_{3} / \mathrm{H}_{2} /$ air $\mathrm{LBVs}$, while the latter was mainly validated for $\mathrm{CH}_{4}$-containing blends. The laminar flame thickness $\delta_{L}$ was computed as $\delta_{L}=$ $\lambda_{\mathrm{u}} / \rho_{\mathrm{u}} c_{\mathrm{p}} S_{\mathrm{L}}^{0}$, with $\lambda_{\mathrm{u}}$ and $c_{\mathrm{p}}$ the unburned gas thermal conductivity and specific heat capacity at constant pressure, respectively, estimated at the temperature of maximum flame temperature gradient, and $S_{\mathrm{L}}^{0}$ 
the measured LBV of the mixture. Effective Lewis numbers $L e_{\text {eff }}$ were calculated following recommendations by Lapalme et al. for multi-component fuels, considering successively individual diffusion of each reactive species in the global remaining mixture, volume-based mixing rule and fuel/oxidizer combination [32].

\section{Results and discussion}

\section{1 $\mathrm{NH}_{3}$-fueled SI engine}

Figure 2 shows the averaged HRR during the combustion of various $\mathrm{NH}_{3}$ and $\mathrm{CH}_{4}$-based fuels in the engine cylinder at $\phi=0.9$ and constant SIT. Supplementary data, including coefficients of variation of the indicated mean effective pressure are available in the Supplemental Material. Hydrogen enrichment causes earlier, faster and more intensive heat release, as seen in Fig. $2 \mathrm{a}$ and $2 \mathrm{c}$ for the $\mathrm{NH}_{3}-$ based and $\mathrm{CH}_{4}$-based fuels, respectively. Unexpectedly, $\mathrm{CH}_{4}$ blending in $\mathrm{NH}_{3}$ results in opposite trends, as showed in Fig.2b: increasing the $\mathrm{CH}_{4}$ fraction in the $\mathrm{NH}_{3}$-based fuel causes a delay, loss of intensity and widening of the HRR peak, even if the $\mathrm{LBV}$ with $\mathrm{CH}_{4}$ is higher than pure $\mathrm{NH}_{3}$.
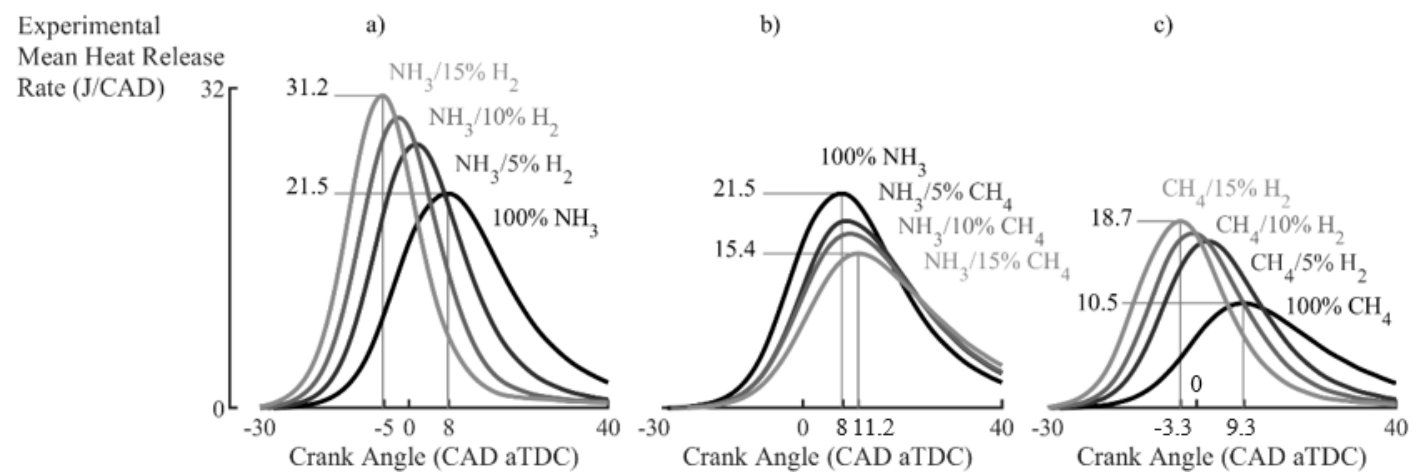

Fig.2. Hydrogen enrichment in ammonia or methane causes earlier, more intense engine heat releases, whereas methane enrichment in ammonia causes a delayed and weakened heat release at $\phi=0.9$ and $\mathrm{SIT}=42 \mathrm{CAD}$ bTDC.

Increasing $\phi$ up to 1.1 results in an increase of the maximum HRR for all mixtures, but does not change qualitatively the previously observed trends for the hydrogen-enriched mixtures as seen in Figs.S1 to S3. However, the combustion duration of $\mathrm{NH}_{3} / \mathrm{CH}_{4}$ mixtures is modified with increasing $\phi$, as observed in Fig.3. For hydrogen-enriched mixtures, the previously observed trend of combustion 
acceleration with increasing $\mathrm{H}_{2}$ fraction and $\phi$ is highlighted as the duration of the first propagation phase CA50-SIT decreases accordingly. For instance, a 15.5CAD decrease is observed for $\mathrm{NH}_{3} / \mathrm{H}_{2}$ blend at $\phi=0.9$ from 0 to $15 \mathrm{vol} . \% \mathrm{H}_{2}$ in the fuel. For the $\mathrm{NH}_{3} / \mathrm{CH}_{4}$, increasing the $\mathrm{CH}_{4}$ fuel fraction affects differently the CA50-SIT as a function of $\phi$ : delayed at $\phi=0.9$ (Fig.3a), not affected at $\phi=1.0$ (Fig.3b) and slightly accelerated at $\phi=1.1$ (Fig.3c). This unexpected behavior indicates different flame development and propagation properties and requires further investigations.
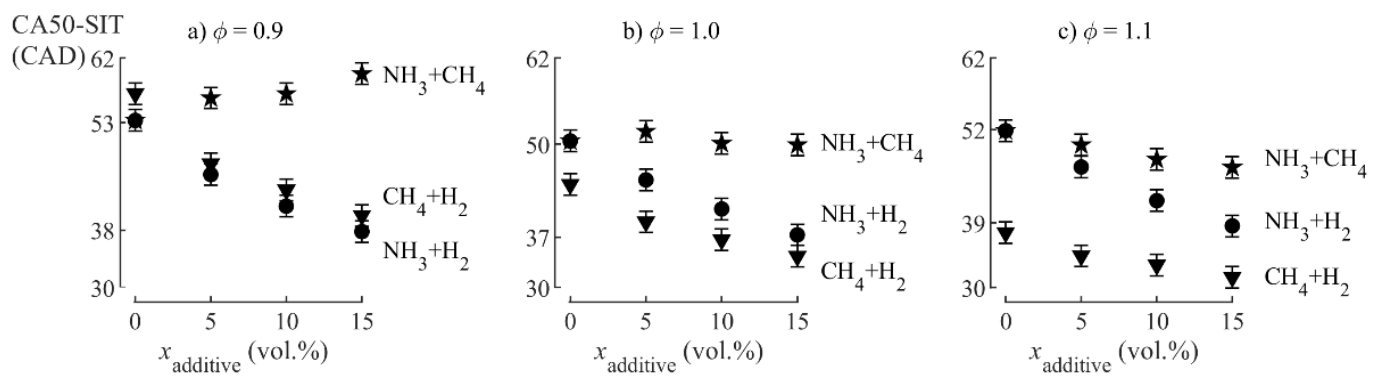

Fig.3. Hydrogen significantly affects the duration of the flame propagation at all equivalence ratios, whereas methane enrichment of ammonia has little influence (SIT=42CAD bTDC).

\subsection{Laminar flames results}

Figure 4 shows experimental LBVs along with kinetic modelling predictions for $\mathrm{NH}_{3}$-based blends. Some experimental values for $\mathrm{CH}_{4} / \mathrm{H}_{2}$ blends can be found in the Supplemental Material. As expected, the magnitudes of the measured LBVs for the ammonia-based blends are very low, about 5 to 6 times smaller than those of methane. Nevertheless, it is interesting to notice that adding $\mathrm{H}_{2}$ or $\mathrm{CH}_{4}$ to the $\mathrm{NH}_{3}$ fuel induces the same LBV increase at $\phi=0.9$ (Fig.4a), and similar effects at $\phi=1.0$ and 1.1 (Figs.4b and 4c). Thus, the LBV does not fully explain the significantly different impacts between hydrogen and methane enrichment observed in the SI engine in Fig.2 and Fig.3. The comparison with the kinetic modeling indicates well predicted trends, but without quantitative agreement and a certain scatter between the mechanisms for $\mathrm{NH}_{3} / \mathrm{H}_{2}$, up to $23 \%$ discrepancy. 
Laminar

Burning Velocity 20 $S_{\mathrm{L}}^{0}\left(\mathrm{~cm} \cdot \mathrm{s}^{-1}\right)$
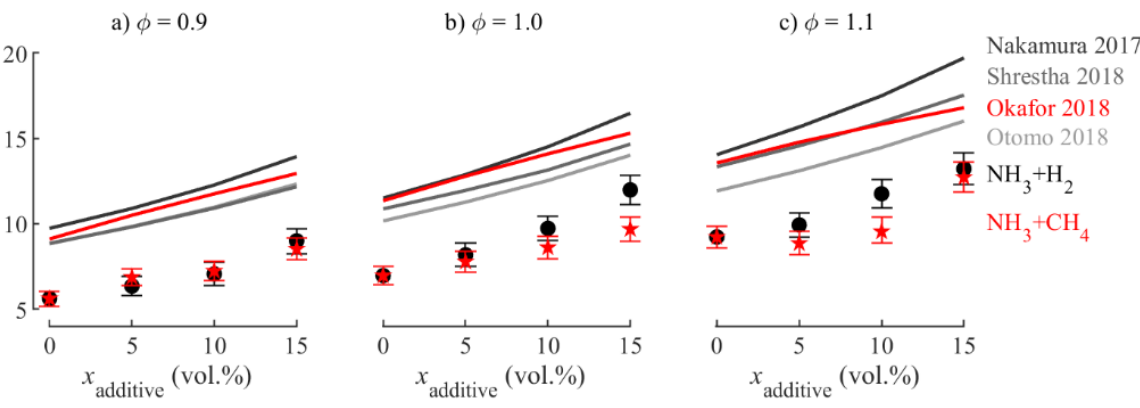

Fig.4. Effect of hydrogen and methane enrichment on the LBV at ignition timing conditions (445K, $0.54 \mathrm{MPa})$.

\subsection{Turbulent flames investigations}

All conditions studied in the turbulent constant-volume vessel and in the SI engine are reported in the Peters-Borghi diagram $[33,34]$ in Fig.5. The engine conditions for $\mathrm{NH}_{3}$-based fuels belong to the thin reaction zone regime, located closer to the upper-right corner of the diagram than usual conventional fuel engine operation due to the very low LBVs of present mixtures. Such conditions, out of the flamelet regime, may be characterized by a distributed combustion, strongly affected by turbulence. This is especially true for very-low-LBV mixtures such as lean $\mathrm{NH}_{3}$ /air mixture. Please note that similar regimes were found in [22], while the flames in [21] belonged to the flamelet regime. The spherical vessel conditions are close to the engine ones, even though slightly shifted towards the bottom-right corner of the diagram because of higher $L_{\mathrm{T}}$ and smaller $u$ '. Thus, the present turbulent flame study is relevant to investigate the differences observed during the engine study in Sec.3.1. No significant difference is observed in Fig. 5 between $\mathrm{NH}_{3} / \mathrm{H}_{2}$ and $\mathrm{NH}_{3} / \mathrm{CH}_{4}$ fuels, indicating similar combustion regimes. 


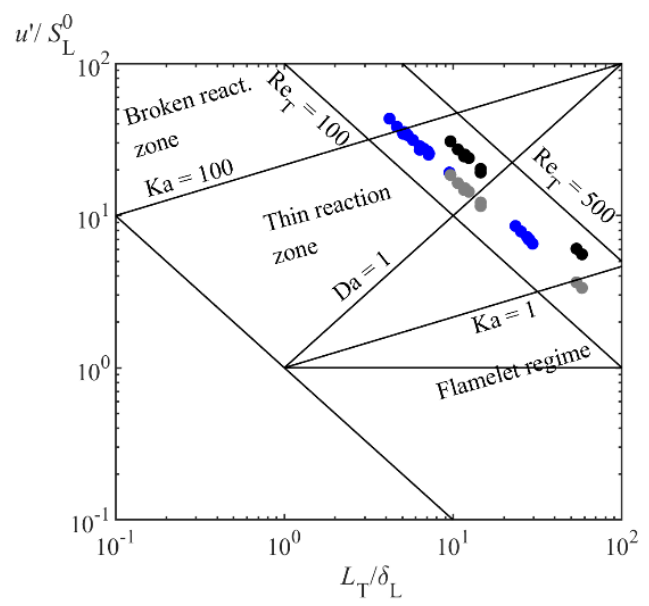

Fig.5. All conditions on Peters-Borghi's diagram. Blue: engine conditions; grey: spherical vessel $\left(\phi=0.9\right.$ and $\left.u^{\prime}=1.04 \mathrm{~m} . \mathrm{s}^{-1}\right)$; black: spherical vessel $\left(\phi=0.9\right.$ and $\left.u^{\prime}=1.73 \mathrm{~m} . \mathrm{s}^{-1}\right)$.

Figure 6 shows the propagation of lean flames at $u^{\prime}=1.04 \mathrm{~m} \cdot \mathrm{s}^{-1}$. The turbulent-to-laminar velocity ratio increases when the flame surface equivalent radius $R_{\mathrm{s}}$ increases, suggesting that combined turbulent wrinkling and stretch effects influence the flame throughout its propagation until the maximum observable radius. Large error bars illustrate the important scatter of the experimental data, mostly due to the non-spherical shape of the flames caused by the turbulence. Notwithstanding, comparing the mean values at constant radius allows one to observe a positive effect of hydrogen enrichment on the turbulent-to-laminar velocity ratio up to a 10 vol. $\% \mathrm{H}_{2}$, then a decrease for 15 vol. $\%$ fuel $\mathrm{H}_{2}$ content. Figure 6 also illustrates the difference in turbulence response between hydrogen and methane enrichment: adding hydrogen or methane in the $\mathrm{NH}_{3}$-based fuel causes respectively an increase or a decrease of the turbulent-to-laminar velocity ratio in comparison to pure $\mathrm{NH}_{3}$. Moreover, it can be observed that the turbulent-to-laminar velocity ratio of $\mathrm{NH}_{3} / \mathrm{H}_{2}$ blends is about twice higher than the one of $\mathrm{CH}_{4} / \mathrm{H}_{2}$ blends and that this difference increases with increasing hydrogen fraction and flame radius. Specifically, a small $\mathrm{H}_{2}$-enrichment causes steep increase of the turbulent-to-laminar velocity ratio versus $R_{\mathrm{S}}$ for the $\mathrm{NH}_{3}$-based fuel but not for the $\mathrm{CH}_{4}$-based fuel. Thus, the turbulent response of $\mathrm{NH}_{3}$ fuels is enhanced by slight hydrogen enrichment, while it remains relatively unchanged for $\mathrm{CH}_{4}$ based mixtures. 


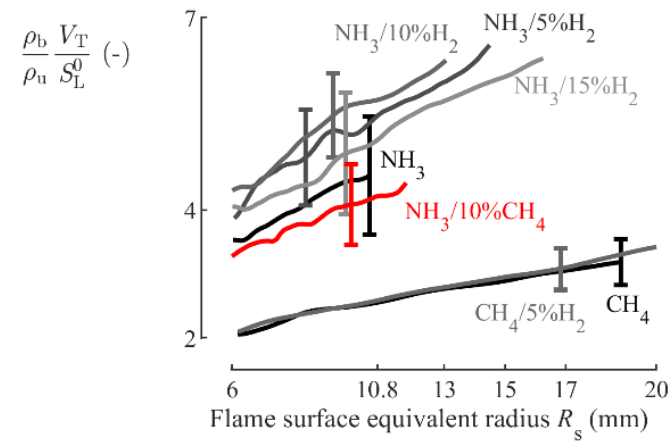

Fig.6. The turbulent-to-laminar velocity ratio increases with the flame surface equivalent radius and is enhanced by hydrogen enrichment but inhibited by methane enrichment $\left(\phi=0.9, u^{\prime}=1.04 \mathrm{~m} / \mathrm{s}\right)$.

The turbulent-to-laminar velocity ratio with $V_{\mathrm{T}}$ value considered at $R_{\mathrm{S}}=10 \mathrm{~mm}$, representative of the turbulence-flame interactions during early flame development [28] is plotted as a function of $u^{\prime} / S_{\mathrm{L}}^{0}$ in Fig.7. First, as expected, increasing the turbulent intensity induces higher turbulent-to-laminar velocity ratios in all cases. Furthermore, the respective enhancing or inhibiting effects of enriching ammonia with $\mathrm{H}_{2}$ or $\mathrm{CH}_{4}$ on the flame turbulence response observed in Fig. 6 are confirmed at increased turbulent intensity and various additive fractions. This observation agrees well with the SI engine results in Sec.3.1, where adding hydrogen caused earlier and stronger heat release, while adding methane caused the opposite (Fig.2). Since no significant LBV gap appeared in Fig. 4 between $\mathrm{H}_{2}$ and $\mathrm{CH}_{4}$ enrichment, their opposite effects on the engine combustion phasing are likely related to the observed turbulenceflame interactions.

However, the unexpected tilt in the turbulent-to-laminar velocity ratio between 10 and $15 \mathrm{vol} . \% \mathrm{H}_{2}$ enrichment observed in Fig.6 is again observed at higher turbulent intensity, suggesting a "bending" effect of higher $x_{\mathrm{H}_{2}}$ on the turbulent burning velocity. Analogous effects were previously observed experimentally [35] and numerically [20], and explained by the merging of flame regions strongly affected by turbulence thus reducing the total flame surface area. Presently, a more likely cause is a modification in the flame response to stretch. Furthermore, it is worth noticing anew that $\mathrm{CH}_{4}$-based mixtures exhibit velocity ratios about twice smaller than $\mathrm{NH}_{3}$-based mixtures, in spite of the factor 
five to six between their respective LBVs in favor of methane. This is likely due to significant differences in the combustion regimes of the two kind of blends, and highlights the limitations of LBV considerations to predict combustion processes in SI engines as underlined in [30].

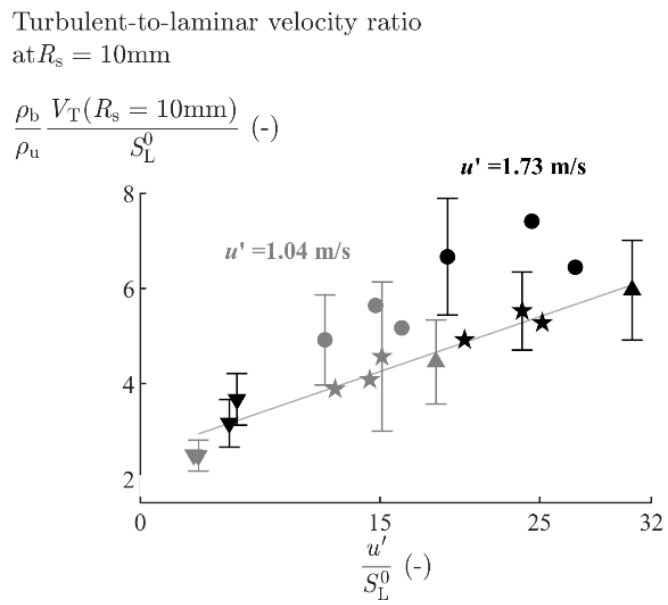

Fig.7. At $R_{\mathrm{s}}=10 \mathrm{~mm}$, the turbulent-to-laminar velocity ratio correlates well with the normalized turbulent intensity, except for ammonia/hydrogen blends. $\boldsymbol{\Delta}$ : $\mathrm{NH}_{3} ; \bullet: \mathrm{NH}_{3}+\mathrm{H}_{2} ; \star$ : $\mathrm{NH}_{3}+\mathrm{CH}_{4} ; \boldsymbol{\nabla}$ : $\mathrm{CH}_{4}+\mathrm{H}_{2} . \phi=0.9$.

Figure 8a shows the dependence of the turbulent-to-laminar velocity ratio on the effective Lewis number: increasing $x_{\mathrm{H}_{2}}$ or $x_{\mathrm{CH}_{4}}$ in the $\mathrm{NH}_{3}$ blends causes respectively a slight decrease or an increase of $L e_{\text {eff. }}$ A qualitative correlation is globally observed showing decrease of the turbulent-to-laminar velocity ratio when $L e_{\text {eff }}$ increases towards unity. This was expected, since the onset of preferential diffusion with decreasing $L e_{\text {eff }}$ amplifies the accelerating effects of turbulence-induced flame wrinkling. On the other hand, Fig.8b shows a global correlation between the velocity ratio and the Markstein lengths $\left(L_{\mathrm{b}}\right)$ measured during the laminar flame experiments, illustrating the different influences of stretch on the flame propagation. Thus, the opposite influence of $\mathrm{H}_{2}$ and $\mathrm{CH}_{4}$ enrichment on the turbulent combustion propagation observed in Fig.7 likely originates from opposite thermodiffusive properties, as well as from different flame response to stretch. $L_{\mathrm{b}}$ remains a valid qualitative evaluator of the turbulent flame-stretch interaction as evidenced in [30] and probably explains the bending effect observed in Fig. 6 and Fig. 7 between 10 and $15 \% \mathrm{H}_{2}$ in the $\mathrm{NH}_{3} / \mathrm{H}_{2}$ blend. 


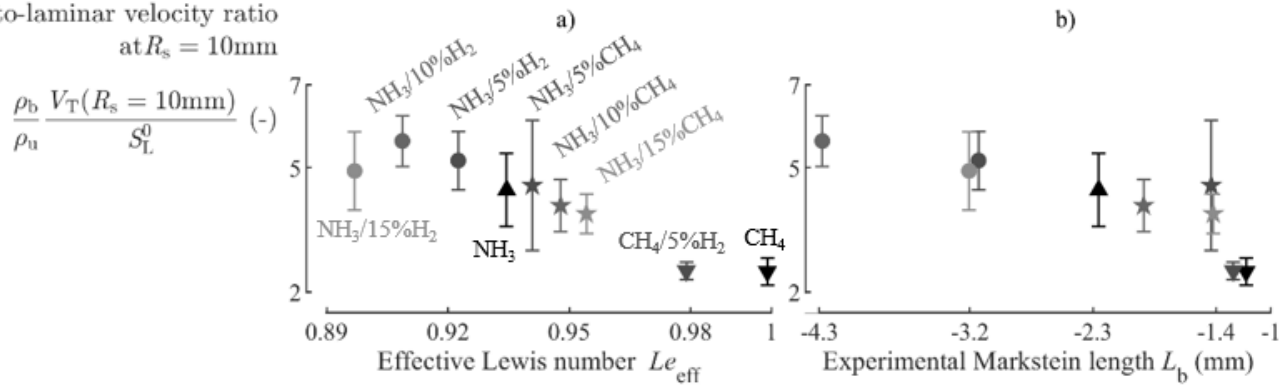

b)

Fig.8. Turbulent-to-laminar velocity ratio varies almost monotonically at $R_{\mathrm{s}}=10 \mathrm{~mm}$ with $L e_{\text {eff }}$ and $L_{\mathrm{b}}$ at $\phi=0.9\left(u^{\prime}=1.04 \mathrm{~m} \cdot \mathrm{s}^{-1}\right)$.

More sophisticated correlations are available in the literature for the turbulent burning velocity $[28,36]$. Since thermo-diffusive and stretch effects show an influence on the ammonia flame response to turbulence, it appears meaningful to include those in a correlation. In Figure 9, experimental turbulent-to-laminar velocity ratios correlate very well with an updated form of the correlation proposed in [36]:

$$
\frac{\rho_{\mathrm{b}}}{\rho_{\mathrm{u}}} \frac{V_{\mathrm{T}}\left(R_{\mathrm{S}}=10 m m\right)}{S_{L}^{0}}=|M a|^{\mathrm{A}} \frac{\mathrm{B}}{L e_{\mathrm{eff}}} \operatorname{Re}_{\mathrm{T}}^{0.25}\left(\frac{u^{\prime}}{S_{\mathrm{L}}^{0}}\right)^{0.3}\left(\frac{p}{p_{\text {ref }}}\right)^{0.2}+\mathrm{C}
$$

with $\mathrm{A}, \mathrm{B}$ and $\mathrm{C}$ constants $\left(\mathrm{A}=0.06\right.$ in Fig.9), $M a=L_{\mathrm{b}} / \delta_{\mathrm{L}}$ the Markstein number of the mixture, and $R e_{\mathrm{T}}=\left(u^{\prime} L_{\mathrm{T}}\right) /\left(S_{\mathrm{L}}^{0} \delta_{\mathrm{L}}\right)$ the turbulent Reynolds number. Therefore, thermo-diffusive properties and flame-stretch interactions appear to have a prominent role in the turbulent combustion of ammonia mixtures. 
Turbulent-to-laminar velocity ratio

at $R_{\mathrm{s}}=10 \mathrm{~mm}$

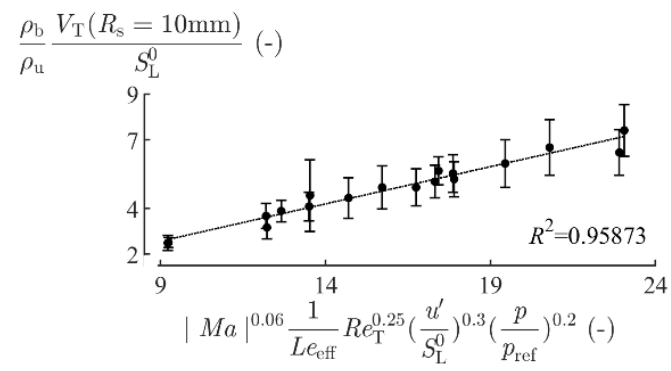

Fig.9. Experimental turbulent-to-laminar velocity ratios correlate well with a $M a$-corrected variation of the correlation proposed by Muppala et al. [36] for all present conditions at $\phi=0.9$.

As turbulence-flame interactions strongly influence the propagation characteristics of the flames, as a function of combustion regimes delimited by characteristic numbers, it appears interesting to suggest a correlation between the turbulent-to-laminar velocity ratio and these characteristic numbers incorporating the various turbulent and chemical scales. Indeed, a very good correlation is found in Fig. 10 between the present velocity data corrected with the associated Damköhler $(D a)$ and Karlovitz numbers for all fuel blends, and expressed as:

$$
\frac{\rho_{\mathrm{b}}}{\rho_{\mathrm{u}}} \frac{V_{\mathrm{T}}\left(R_{\mathrm{s}}=10 \mathrm{~mm}\right)}{S_{L}^{0}}=\mathrm{a} D a K a^{\mathrm{b}}
$$

with $\mathrm{a}=0.1843$ and $\mathrm{b}=1.1694$.

Turbulent-to-laminar velocity ratio

at $R_{\mathrm{s}}=10 \mathrm{~mm}$ corrected with $D a$

$\frac{\rho_{\mathrm{b}}}{\rho_{\mathrm{u}}} \frac{V_{\mathrm{T}}\left(R_{\mathrm{s}}=10 \mathrm{~mm}\right)}{S_{\mathrm{L}}^{0}} \frac{1}{D a}(-)$

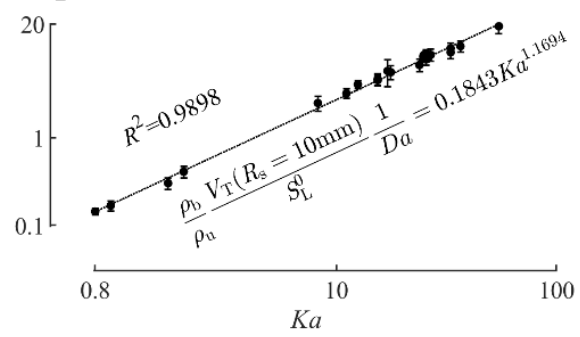

Fig.10. A new correlation of $D a$-corrected turbulent-to-laminar velocity ratios with $K a$ for all conditions of mixtures and turbulence. 


\section{Conclusions}

This work aimed at extending the understanding of $\mathrm{NH}_{3}$ combustion in SI engine conditions. New laminar burning velocity measurements under engine-relevant conditions are presented but do not sufficiently explain the engine combustion behavior. Unprecedented turbulent expanding flame measurements with hydrogen and methane enrichment showed that such combustion occurs in unusual combustion regimes. Enhancing and inhibiting effects of $\mathrm{H}_{2}$ and $\mathrm{CH}_{4}$ enrichment on the flame turbulent response were highlighted and partially linked to the different thermo-diffusive properties and flame stretch response of the fuels. Present experimental results correlate well with the characteristic quantities of turbulent premixed combustion and could explain trends observed in real SI engine operation. Thus, further experiments and modelling efforts including direct numerical simulation would be very valuable to gain further understanding on ammonia turbulent combustion and optimize practical combustion systems.

\section{Acknowledgements}

This research has received funding from the French Government's "Investissement d'Avenir" program: "Laboratoire d'Excellence CAPRYSSES" (Grant NANR-11-LABX-0006-01). The authors would also like to acknowledge Amanda Alves Barbosa for her implication in the flame experiments.

\section{References}

[1] International Energy Agency, The Future of Hydrogen, 2019.

[2] H. Kobayashi, A. Hayakawa, K.D.K.A. Somarathne, E.C. Okafor, Science and technology of ammonia combustion, Proc. Combust. Inst. 37 (2019) 109-133.

[3] A. Valera-Medina, H. Xiao, M. Owen-Jones, W.I.F. David, P.J. Bowen, Ammonia for power, Prog. Energy Combust. Sci. 69 (2018) 63-102.

[4] P. Dimitriou, R. Javaid, A review of ammonia as a compression ignition engine fuel, Int. J. Hydrogen Energy. 45 (2020) 7098-7118. 
[5] J.P. Szybist, D. Splitter, Effects of Fuel Composition on EGR Dilution Tolerance in Spark Ignited Engines, SAE Int. J. Engines. 9 (2) (2016).

[6] A. Hayakawa, T. Goto, R. Mimoto, Y. Arakawa, T. Kudo, H. Kobayashi, Laminar burning velocity and Markstein length of ammonia/air premixed flames at various pressures, Fuel. 159 (2015) 98-106.

[7] A. Ichikawa, A. Hayakawa, Y. Kitagawa, K.D.D. Kunkuma Amila Somarathne, T. Kudo, H. Kobayashi, Laminar burning velocity and Markstein length of ammonia/hydrogen/air premixed flames at elevated pressures, Int. J. Hydrogen Energy. 40 (2015) 9570-9578.

[8] E.C. Okafor, Y. Naito, S. Colson, A. Ichikawa, T. Kudo, A. Hayakawa, H. Kobayashi, Measurement and modelling of the laminar burning velocity of methane-ammonia-air flames at high pressures using a reduced reaction mechanism, Combust. Flame. 204 (2019) 162-175.

[9] C. Lhuillier, P. Brequigny, N. Lamoureux, F. Contino, C. Mounaïm-Rousselle, Experimental investigation on laminar burning velocities of ammonia/hydrogen/air mixtures at elevated temperatures, Fuel. 263 (2020) 116653.

[10] A.A. Konnov, Implementation of the NCN pathway of prompt-NO formation in the detailed reaction mechanism, Combust. Flame. 156 (2009) 2093-2105.

[11] O. Mathieu, E.L. Petersen, Experimental and modeling study on the high-temperature oxidation of Ammonia and related NOx chemistry, Combust. Flame. 162 (2015) 554-570.

[12] H. Nakamura, S. Hasegawa, T. Tezuka, Kinetic modeling of ammonia/air weak flames in a micro flow reactor with a controlled temperature profile, Combust. Flame. 185 (2017) 16-27.

[13] J. Otomo, M. Koshi, T. Mitsumori, H. Iwasaki, K. Yamada, Chemical kinetic modeling of ammonia oxidation with improved reaction mechanism for ammonia/air and ammonia/hydrogen/air combustion, Int. J. Hydrogen Energy. 43 (2018) 3004-3014.

[14] K.P. Shrestha, L. Seidel, T. Zeuch, F. Mauss, Detailed Kinetic Mechanism for the Oxidation 
of Ammonia Including the Formation and Reduction of Nitrogen Oxides, Energy and Fuels. 32 (2018) 10202-10217.

[15] E.C. Okafor, Y. Naito, S. Colson, A. Ichikawa, T. Kudo, A. Hayakawa, H. Kobayashi, Experimental and numerical study of the laminar burning velocity of $\mathrm{CH} 4-\mathrm{NH} 3$-air premixed flames, Combust. Flame. 187 (2018) 185-198.

[16] R. Li, A.A. Konnov, G. He, F. Qin, D. Zhang, Chemical mechanism development and reduction for combustion of NH3/H2/CH4 mixtures, Fuel. 257 (2019) 116059.

[17] C. Lhuillier, P. Brequigny, F. Contino, C. Mounaïm-Rousselle, Combustion Characteristics of Ammonia in a Modern Spark-Ignition Engine, SAE Tech. Pap. (2019) 2019-24-0237.

[18] C. Lhuillier, P. Brequigny, F. Contino, C. Mounaïm-Rousselle, Performance and Emissions of an Ammonia-Fueled SI Engine with Hydrogen Enrichment, SAE Tech. Pap. (2019) 2019-240137.

[19] C. Lhuillier, P. Brequigny, F. Contino, C. Mounaïm-Rousselle, Experimental study on ammonia/hydrogen/air combustion in spark ignition engine conditions, Fuel. 269 (2020) 117448.

[20] T. Nilsson, H. Carlsson, R. Yu, X.S. Bai, Structures of turbulent premixed flames in the high Karlovitz number regime - DNS analysis, Fuel. 216 (2018) 627-638.

[21] A. Ichikawa, Y. Naito, A. Hayakawa, T. Kudo, H. Kobayashi, Burning velocity and flame structure of $\mathrm{CH} 4 / \mathrm{NH} 3 /$ air turbulent premixed flames at high pressure, Int. J. Hydrogen Energy. 44 (2019) 6991-6999.

[22] R. Ichimura, K. Hadi, N. Hashimoto, A. Hayakawa, H. Kobayashi, O. Fujita, Extinction limits of an ammonia/air flame propagating in a turbulent field, Fuel. 246 (2019) 178-186.

[23] R.G. Abdel-Gayed, D. Bradley, M.N. Hamid, M. Lawes, Lewis number effects on turbulent burning velocity, Proc. Combust. Inst. 20 (1984) 505-512. 
[24] A.N. Lipatnikov, J. Chomiak, Molecular transport effects on turbulent flame propagation and structure, Prog. Energy Combust. Sci. 31 (2005) 1-73.

[25] P. Brequigny, F. Halter, C. Mounaïm-Rousselle, Lewis number and Markstein length effects on turbulent expanding flames in a spherical vessel, Exp. Therm. Fluid Sci. 73 (2016) 33-41.

[26] O.F. Y. Xia, G. Hashimoto, K. Hadi, N. Hahimoto, A. Hayakawa, H. Kobayashi, Turbulent burning velocity of ammonia/oxygen/nitrogen premixed flame in O2-enriched air condition, Fuel. 268 (2020) 117383.

[27] B. Galmiche, F. Halter, F. Foucher, Effects of high pressure, high temperature and dilution on laminar burning velocities and Markstein lengths of iso-octane/air mixtures, Combust. Flame. 159 (2012) 3286-3299.

[28] P. Brequigny, C. Endouard, F. Foucher, C. Mounaïm-Rousselle, Improvement of Turbulent Burning Velocity Measurements by Schlieren Technique, for High Pressure Isooctane-Air Premixed Flames, Combust. Sci. Technol. (2019) 1-17.

[29] B. Galmiche, N. Mazellier, F. Halter, F. Foucher, Turbulence characterization of a highpressure high-temperature fan-stirred combustion vessel using LDV, PIV and TR-PIV measurements, Exp Fluids. 55 (2014) 1636.

[30] P. Brequigny, F. Halter, C. Mounaïm-Rousselle, T. Dubois, Fuel performances in SparkIgnition (SI) engines: Impact of flame stretch, Combust. Flame. 166 (2016) 98-112.

[31] D.G. Goodwin, R.L. Speth, H.K. Moffat, B.W. Weber, Cantera: An object-oriented software toolkit for chemical kinetics, thermodynamics, and transport processes., Version 2.4.0. (2018), available at $<$ https://cantera.org/>.

[32] D. Lapalme, R. Lemaire, P. Seers, Assessment of the method for calculating the Lewis number of $\mathrm{H} 2 / \mathrm{CO} / \mathrm{CH} 4$ mixtures and comparison with experimental results, Int. J. Hydrogen Energy. 42 (2017) 8314-8328. 
[33] R. Borghi, Mise au point sur la structure des flammes turbulentes, J. Chim. Phys. 81 (1984) $361-370$.

[34] N. Peters, Laminar flamelet concepts in turbulent combustion, Proc. Combust. Inst. 21 (1988) $1231-1250$.

[35] S.A. Filatyev, J.F. Driscoll, C.D. Carter, J.M. Donbar, Measured properties of turbulent premixed flames for model assessment, including burning velocities, stretch rates, and surface densities, Combust. Flame. 141 (2005) 1-21.

[36] S.P. Reddy Muppala, N.K. Aluri, F. Dinkelacker, A. Leipertz, Development of an algebraic reaction rate closure for the numerical calculation of turbulent premixed methane, ethylene, and propane/air flames for pressures up to $1.0 \mathrm{MPa}$, Combust. Flame. 140 (2005) 257-266. 


\section{List of Figure Captions}

Fig.1. Example of double Schlieren images of a $\mathrm{NH}_{3} /$ air turbulent flame at $u^{\prime}=1.73 \mathrm{~m} . \mathrm{s}^{-1}$.

Fig.2. Hydrogen enrichment in ammonia or methane causes earlier, more intense engine heat releases, whereas methane enrichment in ammonia causes a delayed and weakened heat release at $\phi=0.9$ and SIT $=42 \mathrm{CAD}$ bTDC.

Fig.3. Hydrogen significantly affects the duration of the flame propagation at all equivalence ratios, whereas methane enrichment of ammonia has little influence (SIT=42CAD bTDC).

Fig.4. Effect of hydrogen and methane enrichment on the LBV at ignition timing conditions (445K, $0.54 \mathrm{MPa})$.

Fig.5. All conditions on Peters-Borghi's diagram. Blue: engine conditions; grey: spherical vessel $\left(\phi=0.9\right.$ and $\left.\mathrm{u}^{\prime}=1.04 \mathrm{~m} \cdot \mathrm{s}^{-1}\right)$; black: spherical vessel $\left(\phi=0.9\right.$ and $\left.\mathrm{u}^{\prime}=1.73 \mathrm{~m} \cdot \mathrm{s}^{-1}\right)$.

Fig.6. The turbulent-to-laminar velocity ratio increases with the flame surface equivalent radius and is enhanced by hydrogen enrichment but inhibited by methane enrichment $\left(\phi=0.9, \mathrm{u}^{\prime}=1.04 \mathrm{~m} / \mathrm{s}\right)$.

Fig.7. At $\mathrm{R}_{\mathrm{s}}=10 \mathrm{~mm}$, the turbulent-to-laminar velocity ratio correlates well with the normalized turbulent intensity, except for ammonia/hydrogen blends. $\boldsymbol{\Delta}: \mathrm{NH}_{3} ; \bullet: \mathrm{NH}_{3}+\mathrm{H}_{2} ; \star$ : $\mathrm{NH}_{3}+\mathrm{CH}_{4} ; \mathbf{\nabla}$ : $\mathrm{CH}_{4}+\mathrm{H}_{2} . \phi=0.9$.

Fig.8. Turbulent-to-laminar velocity ratio varies almost monotonically at $R_{s}=10 \mathrm{~mm}$ with $\mathrm{Le}_{\text {eff }}$ and $\mathrm{L}_{b}$ at $\phi=0.9\left(\mathrm{u}^{\prime}=1.04 \mathrm{~m} \cdot \mathrm{s}^{-1}\right)$.

Fig.9. Experimental turbulent-to-laminar velocity ratios correlate well with a Ma-corrected variation of the correlation proposed by Muppala et al. [36] for all present conditions at $\phi=0.9$.

Fig.10. A new correlation of Da-corrected turbulent-to-laminar velocity ratios with Ka for all conditions of mixtures and turbulence. 


\section{List of supplemental material}

TurbulentFlame_85NH3_15CH4_ER0-9_up1-73ms_edit.mp4

TurbulentFlame_85NH3_15H2_ER0-9_up1-73ms_edit.mp4

TurbulentFlame_90NH3_10H2_ER0-9_up1-73ms_edit.mp4

TurbulentFlame_CH4_ER0-9_up1-73ms_edit.mp4

TurbulentFlame_NH3_ER0-9_up1-73ms_edit.mp4

Lhuillier_etal_Supplementary_data.xlsx

Lhuillier_etal_SMM.docx:

Fig. S1. At $\phi=1.0$, hydrogen enrichment in ammonia or methane causes earlier, more intense engine heat releases, whereas methane enrichment in ammonia does not accelerate the heat release (SIT $=42$ CAD bTDC).

Fig. S2. At $\phi=1.1$, hydrogen enrichment in ammonia or methane causes earlier, more intense engine heat releases, and methane enrichment in ammonia produces a slight but similar effect (SIT=42 CAD bTDC).

Fig. S3. Experimental engine combustion phasing. Top row: $\mathrm{NH}_{3} / \mathrm{H}_{2}$, middle row: $\mathrm{CH}_{4} / \mathrm{H}_{2}$, bottom row: $\mathrm{NH}_{3} / \mathrm{CH}_{4}$. See the separate table in the $\mathrm{SM}$ for values.

Fig. S4. Evolution of the turbulent-to-laminar velocity ratio as a function of the flame surface equivalent radius for various fuels at $\phi=0.9$.

Fig. S5. Measured Markstein lengths at $445 \mathrm{~K}$ and $0.54 \mathrm{MPa}$ indicate comparatively stronger flamestretch interactions for lean mixtures, mainly relevant for $\mathrm{NH}_{3} / \mathrm{H}_{2}$ mixtures. 